quản, làm tổn thương do axit. Vì vậy, việc cai thuốc lá và hạn chế sử dụng rượu, bia được khuyến khích để làm giảm nguy cơ mắc các triệu chứng của GERD [4].

Triệu chứng ợ chua, ợ hơi chiếm tỉ lệ cao nhất $(88,33 \%)$ và tổng điểm GERD $\mathrm{Q}$ trung bình của bênh nhân là $10,42 \pm 1,72$ điểm. Kết quả nghiên cứu của chúng tôi cũng phù hợp với nghiên cứu của Đoàn Thị Hoài (2006) khi nghiên cứu trên 71 bênh nhân tại Bênh viên Bach Mai và Bệnh viện Đại học $Y$ Hà Nội, tỷ lệ bệnh nhân ợ chua chiếm tỉ lệ $87,7 \%$ và tổng điểm GERD Q trung bình 10,5 $\pm 3,1$ điểm [1].

\section{KẾT LUÂN}

1. Tuổi trung bình trong nghiên cứu là 51,95 $\pm 15,94$ tuổi. Tỉ lệ nữ cao hơn nam (Nữ: $66,67 \%$, Nam: 33,33\%). Phần lớn bệnh nhân là lao động trí óc $(38,33 \%)$. Thời gian bị bệnh chủ yếu từ 6 đến 12 tháng $(61,67 \%)$. Có $30,0 \%$ bệnh nhân có sử dụng bia rượu, $21,67 \%$ có thuốc lá, 33,33\% thường xuyên uống cà phê, $55 \%$ sử dụng thuốc giảm đau nonsteroid; $38,33 \%$ bệnh nhân thừa cân và béo phì.

2. Triệu chứng ợ chua, ợ hơi chiếm tỉ lệ cao nhất $(88,33 \%)$. Các triệu chứng nuốt chua và ợ nóng cũng chiếm tỉ lệ cao (83,33\% và $71,67 \%)$. Tổng điểm GERD $Q$ trung bình của bệnh nhân khi vào viện là $10,42 \pm 1,72$.

\section{TÀI LIÊU THAM KHẢO}

1. Đoàn Thị Hoài (2006), Nghiên cứu đặc điểm lâm sàng, hình ảnh nội soi - mô bênh học và đo $\mathrm{pH}$ thực quản liên tục 24h trong GËRD, Luận văn Thạc sĩ y học, Trường đại học Y Hà Nôi.

2. El-Serag H.B., Sweet S., Winchester C.C. và cộng sự. (2014). Update on the epidemiology of gastro-oesophageal reflux disease: a systematic review. Gut, 63(6), 871-880.

3. Li W., Zhang S.-T., và Yu Z.-L. (2008). Clinica and endoscopic features of Chinese reflux esophagitis patients. World J Gastroenterol WJG, 14(12), 1866-1871.

4. Ness-Jensen E. và Lagergren J. (2017). Tobacco smoking, alcohol consumption and gastrooesophageal reflux disease. Best Pract Res Clin Gastroenterol, 31(5), 501-508.

5. Nocon M., Labenz J., Jaspersen D. và công sứ. (2007). Association of body mass index with heartburn, regurgitation and esophagitis: results of the Progression of Gastroesophageal Reflux Disease study. J Gastroenterol Hepatol, 22(11), 1728-1731.

6. Pace F., Bollani S., Molteni P. và cộng sự (2004). Natural history of gastro-oesophageal reflux disease without oesophagitis (NERD)--a reappraisal 10 years on. Dig Liver Dis Off J Ital Soc Gastroenterol Ital Assoc Study Liver, 36(2), 111-115.

7. Ruigómez A., Wallander M.-A., Johansson S. và cộng sự. (2009). Irritable bowel syndrome and gastroesophageal reflux disease in primary care: is there a link. Dig Dis Sci, 54(5), 1079-1086.

8. Sandhu D.S. và Fass R. (2018). Current Trends in the Management of Gastroesophageal Reflux Disease. Gut Liver, 12(1), 7-16.

\title{
NHÂN MỘT TRƯờNG HỢP UNG THƯ DẠ DÀY SỚM: CHẨN ĐOÁN VÀ ĐIỀU TRI
}

\author{
Vũ Văn Khiên' ${ }^{1}$ Nguyễn Quang Duật ${ }^{2}$,Trần Thị Huyền Trang ${ }^{1}$, \\ Nguyễn Thị Phương Liên ${ }^{1}$, Nguyễn Văn Mạnh ${ }^{1}$, Phạm Hồng Khánh ${ }^{2}$,
}

\section{TÓM TẮT}

Đặt vấn đề: Ung thư dạ dày đứng hàng thứ 5 trong các bệnh ung thư trên thế giới và đứng hàng thứ tư trong các bệnh ung thư tại Việt Nam. Tuy nhiên, phần lớn bệnh nhân khi đến viện đều ở giai đoan muôn. Do vấy, phát hiện sớm và điều tri sớm đóng vai trò quan trọng, liên quan chặt chẽ đến thời gian sống của bệnh nhân. Chúng tôi trình bày về đăc điểm lâm sàng, nội soi, mô bệnh học và phương thức điều trị cho 01 bệnh nhân UTDD sớm. Ca lâm sàng: Bệnh nhân nữ, 56 tuổi. Từ 08/2020, bệnh nhân có

\section{${ }^{1}$ Bệnh viện TWQD 108}

Bềnh viến 103 - Hoc viện Quân y

Chịu trách nhiệm chính: Vũ Văn Khiên

Email: vuvankhien108@yahoo.com.vn

Ngày nhận bài: 13.8.2021

Ngày phản biên khoa hoc: 4.10.2021

Ngày duyệt bài: 15.10 .2021 triệu chứng: Đau thượng vi, khó tiêu, không gầy sút cân. Từ 09/2020-09/2021, bệnh nhân đã được nội soi da dày (06 lần) và sinh thiết 06 lần. Kết quả nổi soi: loét góc bờ cong nhỏ, kích thước $1 \mathrm{~cm}$, bề mặt không nhẵn. Kết quả mô bênh họ: có $1 / 6$ lần sinh thiết, chúng tôi tìm thấy tế bào ung thư (lân sinh thiết cuối cùng: 09/2021). Có 3/6 lần (50\%) có loạn sản tế bào. Bệnh nhân đã được phấu thuật qua nội soi. Kết quả sau mổ: Ung thư biểu mô tuyển, biệt hóa cao, tại góc bờ cong nhỏ dạ dày, pT1aMONO. Sau mổ, bệnh nhân ổn định, không có biến chứng và ra viện. Kết luận: Nội soi và sinh thiết đóng vai trò quan trọng trong phát hiện hiện sớm ung thư dạ dày.

Tư khóa: Ung thư dạ dày, cắt hạ niêm mạc qua nội soi, mô bệnh học

\section{SUMMARY \\ CASE OF EARLY GASTRIC CANCER: DIAGNOSIS AND TREATMENT}


Introduction: Gastric cancer is the fifth most common malignancy worldwide, and the fourth cause among all malignancy in Vietnam. However, the majority of patients arriving at the hospital are in the late stage. We present the clinical, endoscopic, histopathological and treatment characteristics of 01 patient with early gastric cancer.Case presentation: Female patient, 56 years old. From August 2020, the patient has symptoms: epigastric pain, indigestion, no weight loss. From 09/2020-09/2021, the patient had upper GI endoscopy (06 times) and biopsies (06 times). Endoscopy results: small curvilinear ulcer, size $1 \mathrm{~cm}$, surface is not smooth. Histopathological results: 1/6 biopsies, we found cancer cells (last biopsy: $09 / 2021)$. There were $3 / 6$ times $(50 \%)$ with gastric dysplasia. The patient underwent laparoscopic surgery. Postoperative results: adenocarcinoma, highly differentiated, at the small curvature of the stomach, pT1aM0N0. After surgery, the patient was stable, without complications and was discharged from the hospital. Conclusion: Endoscopy and biopsy play an important role in early detection of gastric cancer.

Key words: Gastric cancer; endoscopic submucosal dissection, histopathology

\section{I. ĐẶT VẤN ĐỀ}

Thống kê của Globocan năm 2020 cho biết ung thư da dày (gastric cancer) đứng hàng thứ 5 trong các loại ung thư cho cả hai giới (nam và nữ). Chỉ tính riêng trong năm 2020, số bệnh nhân nam mắc ung thư dạ dày (UTDD) là 719.523 ca chiếm tỷ lệ 7,1\% trong tổng số các bệnh ung thư ở nam trên toàn thế giới và đứng hàng thứ 4 trong các bệnh ung thư hay gặp ở nam giới [1]. Tần suất mắc UTDD có sự khác biệt giữa các châu lục, tăng cao ở vùng đông bắc á của châu Á (Hàn Quốc, Nhật Bản, Mông Cổ...), nơi có tỷ lệ nhiễm Helicobacter pylori ( $\mathrm{H}$. pylori) tăng cao trong cộng đồng. Tại Nhật Bản, Hàn Quốc.. đã có các chương trình sàng lọc và điều trị sớm UTDD, thông qua các chương trình khám sàng lọc và điều trị qua nội soi bằng các kỹ thuật cắt niểm mạc qua nội soi (endoscopic mucosal resection: EMR) và cắt hạ niêm mạc qua nội soi (endoscopic submucosal dissection: ESD) [2]. Kỹ thuật ESD phụ thuộc rất nhiều yếu tố như: kinh nghiệm người làm nội soi, trang thiết bị và vai trò của giải phẫu bệnh... Tại Việt Nam, do còn thiếu trang thiết và thiếu kinh nghiệm, nên kỹ thuật ESD triển khai còn rất ít và chỉ thực hiện ở các bệnh viện lớn. Chúng tôi trình bày $01 \mathrm{ca}$
UTDD sớm, được theo dõi định kỳ, chẩn đoán và điều trị kịp thời bằng phẫu thuật nội soi.

\section{MINH HOA LÂM SÀNG}

Bệnh nhân Vương Thị X - Nũ̃, sinh năm 1965, hiện đang sinh sống tại Hà Nội. Bệnh nhân không có tiền sử uống rượu bia, gia đình không có ai bi ung thư da dày và các bênh lý da dày khác.

Tháng 08/2020, bênh nhân thấy đau âm vùng thượng vị, khó tiêu, ăn không ngon, nhưng không thấy sút cân, không buồn nôn và không nôn, đại tiểu tiện bình thường. Đầu tháng 09/2020, bệnh nhẩn đến bệnh viện 01 bệnh viện tư' (Hà Nội) kiểm tra toàn diện, nội soi dạ dày và đại tràng gây mê. Kết quả nội soi đại tràng: bình thường. Kết quả nội soi dạ dày: Loét góc bờ cong nhỏ $(B C N)$, kích thước $1 \mathrm{~cm}$, bề mặt không nhẵn. Kết quả mô bệnh học $(\mathrm{MBH})$ : Khổng thấy tế bào ung thư, dị sản ruột và loạn sản nặng. Phác đồ điêu trị: PPI+ photphalugel+ Bioflora

Kết quả khám tại bệnh viện TWQĐ 108

Lần 1. Ngày 10/09/2020, bệnh nhân đến bệnh viện TWQĐ 108 nội soi lại dạ dày, với kết quả chẩn đoán: Loét cũ góc bờ cong nhỏ, kích thước $1 \mathrm{~cm}$. $\mathrm{H}$. pylori $(+)$. Kết quả GPB: Viêm niêm mạc dạ dày mạn tính, hoạt động nhẹ, dị sản ruột, loạn sản độ cao. Bệnh nhân từ chối điều trị ESD. Bệnh nhân tiếp tục điêu trị nội khoa.

Lần 2. Ngày $28 / 10 / 2020$, nội soi dạ dày lần 2 : Loét góc $B C N$, kích thước $1 \mathrm{~cm}$, bề mặt không nhẵn. Kết quả $\mathrm{MBH}$ : Viêm niêm mạc dạ dày mạn tính, hoạt động mạnh, dị sản ruột, teo vừa. Không thấy loạn sản hay ung thư trền các mảnh sinh thiết. Bệnh nhân tiếp tục điều trị nội khoa.

Lần 3. Ngày 02/12/2020, nội soi dạ dày lần 3 : Loét góc $B C N$, bề mặt không nhẵn. $H$. pylori (+). Kết quả MBH: Viêm niêm mạc dạ dày mạn tính, dị sản ruột, loạn sạn độ cao. Bệnh nhân tiếp tục điều trị nội khoa.

Lần 4. Ngày 24/12/2020, nội soi dạ dày lần 4 : Loét góc $B C N$ đã liền sẹo, viêm trợt niêm mạc hang vị. $\mathrm{H}$. pylori (+). Kết quả $\mathrm{MBH}$ : Viêm niêm mac da dày man tính, không có tế bào ung thư trển các mảnh sinh thiết. Bệnh nhân tiếp tục được theo dõi. Tuy nhiên, do đại dịch COVID-19, bệnh nhân không đến khám theo định kỳ đã hẹn.
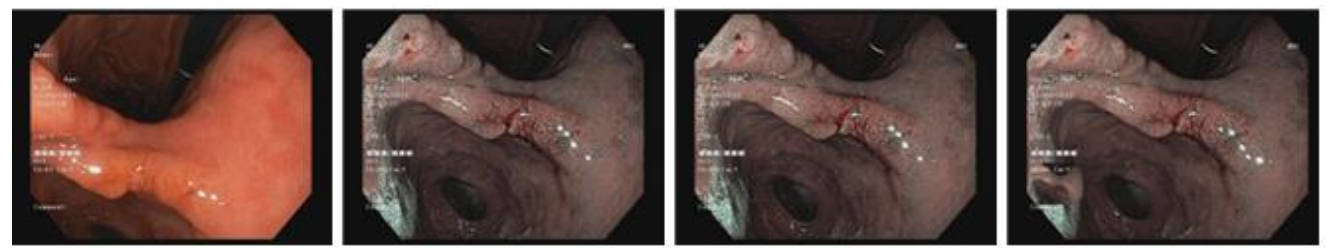

Hình 1. Kêt quả nội soi dạ dày lân thứ 5 (14/09/2021) 
Lần 5. Ngày 14/09/2021, nội soi dạ dày lần 5 : Loét góc $\mathrm{BCN}$, bề mặt không nhẵn, kích thước $1,5 \times 1,0 \mathrm{~cm}$. H. pylori (+). Kết quả MBH: Ổ loét mạn tính ở góc BCN dạ dày đã ung thư hóa (ung thư biểu mô tuyến, biệt hóa vừa, xâm nhậm, $\mathrm{H}$. pylori dương tính.

Ngày 20/09/2021, bệnh nhân được điều trị phẫu thuật qua nội soi. Chẩn đoán sau mổ: Ung thư biểu mô tuyênn, biệt hóa cao, tại góc bờ cong nhỏ dạ dày, pT1aMONO. Ngày 28/09/2021, bệnh nhân bình phục, ăn uống tốt, đại tiểu tiện bình thường và ra viện.

\section{BÀN LUÂ̂N}

Đây là một trường hợp UTDD sớm, được giám sát liên tục, từ khi bệnh khởi phát từ ổ loét nhỏ $(1 \mathrm{~cm})$ tại góc $B C N$, đến khi chuyển thành ung thư giai đoạn sớm, và điều trị kịp thời-triêt để. Sau đây, chúng tôi đưa ra một số vấn đề bàn luận như sau:

1. Bàn về triệu chứng lâm sàng của UTDD sớm. Các kết quả nghiên cứu trên thế giới, cũng như trong nước đều thừa nhận UTDD sớm hầu như không có các triêuu chứng, hoặc triệu chứng không điển hình, dễ bỏ qua và dễ nhầm lẫn sang các bệnh lý khác như khó tiêu chức năng...Trên bệnh nhân này, khởi phát với các triệu chứng gồm đau nhẹ thượng vị, ăn chóng no và đầy bụng. Các triệu chứng này đã giảm nhanh khi sử dụng các thuốc ức chế bơm proton kết hợp với kháng sinh diệt trừ $\mathrm{H}$. pylori. Các triệu chứng này không xuất hiện trong thời gian khá dài $(01-09 / 2021)$ và làm người bệnh chủ quan không đi khám bệnh. Do vậy, triệu chứng lâm sàng của UTDD sớm chỉ là thông số tham khảo. Nội soi định kỳ và sinh thiết làm MBH đóng vai trò quan trọng trong sàng lọc phát hiện sớm UTDD.

2. Bàn luận về hình ảnh nội soi và mô bệnh học của UTDD sớm. Hình ảnh đại thể của UTDD sớm trên nội soi được chia thành các type như sau: type I- dạng lồ hoăc dạng polyp; type II-danng phẳng và chia thành 3 type: II a (phẳng gồ), II $\mathrm{b}$ (phẳng dẹt), II $\mathrm{c}$ (phẳng lõm); type III -dang loét. Tỷ lệ type I chiếm $20 \%$, type III chiếm từ 20-40\%. Đối chiếu với bệnh nhân, kết quả nội soi xếp vào type III: loét trên bề mặt. Nhật Bản là quốc gia hàng đâu, có kinh nghiệm trong nhận biết UTDD giai đoạn sớm trên nội soi. Nội soi ánh sáng trắng và nội soi phóng đại với dải tần ánh sáng hẹp (narrow band imaging: NBI) đều có thể giúp phát hiện sớm UTDD.

Các dấu hiệu trên nội soi với UTDD sớm bao gồm [3]

*Bờ tổn thương được phân định rõ ràng

*Biến đổi mâu sắc/hoặc thay đổi trên bề mặt tổn thương

*Trên NBI: Bất thường về vi mạch và cấu truc bề mặt của tổn thương

Trền bênh nhân này, trong quá trình nôii soi, mặc dù tổn thương còn nhỏ $(1 \mathrm{~cm})$, nhưng các lần nội soi đều thấy bề mặt của tổn thương không đều. Kết quả này thể hiện rõ nét nhất trong lần nội soi cuối cùng (lần 5) trên nội soi ánh sáng trẳng và trên nội soi dải tần ánh sáng hẹp. Ngày nay, với các phương tiện hiện đại, ở các nước tiên tiến cho rằng nếu hình ảnh nội soi của UTDD giai đoạn sớm đã điển hình thì không cần phải làm sinh thiết. Nếu sinh thiết nhiều mảnh và sinh thiết nhiều lần, dễ tạo ra sơ sẹo tại tổn thương, gây khó khăn khi can thiệp qua nội soi bằng EMR hoặc ESD. Gần đây, Nishitani $M$ và CS [4] đã thực hiện nghiên cứu hồi cứu trên 858 bệnh nhân UTDD giai đoạn sớm và đưa ra kết Iuận: Nếu làm sinh thiết cho UTDD sớm, thì chỉ cần sinh thiết 02 mảnh là vừa đủ.

3. Bàn luận về điều trị UTDD sớm. Tại Việt Nam, do điều kiện trang thiết bị hạn chể, kinh nghiệm chưa nhiều, do vậy, khi phát hiện tổn thương nghi ngờ, đều phải tiến hành sinh thiết. Diễn tiến UTDD trải qua các bước sau: tế bào bình thường, viêm teo, dị sản, loạn sản và cuối cùng là ung thư. Do vậy, mô bệnh học đóng vai trò quan trọng trong chẩn đoán UTDD. Trong nghiên cứu này, trong tổng 6 lần nội soi đều làm sinh thiết. Kết quả mô bênh hoc cho biết có $5 / 6$ lần sinh thiết không tìm thây tế bào ung thư, nhưng có $3 / 6$ lần $(50 \%)$ có loạn sản tế bào. Tại Nhật Bản và một số quốc gia khác cho rằng loạn sản tế bào ở dạ dày (gastric dysplasia), nhất là khi có loan sản mức độ cao thì được coi là tiền ung thư (premalignant) và cần phải điều trị triệt để. Tuy nhiên, quan điểm này chưa được các nước phương Tây ủng hộ [5]. Do vậy, ở Việt Nam, quan điểm điều trị triêt căn cho loạn sản độ cao còn chưa thống nhất và cần phải có sự đồng thuận trong hiệp hội chuyên ngành. Siêu âm nội soi (endoscopic ultrasound: EU) rất có giá trị giúp đánh giá sự xâm lấn và di căn hạnh đối với UTDD. Tuy nhiên, kỹ thuật này chưa được ứng dụng rộng rãi với nhiều lý do khách quan khác nhau. Với những bệnh nhân đã có chẩn đoán xác định là ung thư dạ dày, thì điều tri phẫu thuật triệt để là ưu tiên hàng đầu, để phòng tránh tái phát và di căn ung thư và đây chính là lý do chúng tôi lựa chọ phẫu thuât cho bệnh nhân này. Trong tương lai, muốn phát triển 
kỹ thuật ESD cần rất nhiều yếu tố như: trang thiết bị, kinh nghiệm thực hành, vai trò của giải phẫu bệnh...

\section{KẾT LUẬN}

Nội soi da dày thường quy và sinh thiết làm mô bệnh học đóng vai trò quan trọng giúp phát hiện sớm ung thư dạ dày tại Việt Nam.

TÀl LIỆ THAM KHẢO

1. Sung $\mathbf{H}$, Ferlay $\mathbf{J}$, Siegel $\mathbf{R L}$, et al. Globocal cancer statistics 2020: GLOBOCAN estimates of incidence and mortality worldwide for 36 cancers in 185 countries. CA Cancer Journal Clinical 2021;71; 209-249

2. Kim 'SG, Park CM, Lee NR, et al. Long-term clinical outcomes of endoscopic submucosal dissection in patients with early gastric cancer: A prospective multicenter cohort study. Gut and Liver 2018;12(4): 402-410

3. Yao K. The endoscopic diagnosis of early gastric cancer. Annals of Gastroenterology 2013;26: 11-22

4. Nishitani M, Yoshida N, Tsuji S, et al. Optimal number of endoscopic biopsies for diagnosis of early gastric cancer. Endoscopy International Open 2019;07: E1683-E1690

5. Sung JK. Diagnosis and management of gastric dysplasia. Korean J Intern Med 2016;31: 201-209

\section{ĐÁNH GIÁ KẾT QUẢ ĐÎ̀U TRI VIÊM KẾT MẠC Dİ ỨNG THỂ THEO MÙA VÀ QUANH NĂM BẰNG NƯỚC MẮT NHÂN TẠO KHÔNG Có CHẤT BẢO QUẢN}

\section{TÓM TẮT}

Hình thái lâm sàng viêm kết mạc di ứng theo mùa, quanh năm của bệnh viêm kết mạc dị ứng thường bị bỏ qua, dễ nhầm lâ̂n với triêu chứng măt kích ứng tam thời với gió, bụi hay viêm kết mạc do các yếu tố nhiễm trùng.Thực tế khi được chẩn đoán, bệnh nhân sẽ được điêu trị ngay bằng các thuốc kháng dị ứng trong khi chưa thực sự cần thiết.Nghiên cứu mô tả, can thiệp lâm sàng so sánh trước sau và không đối chứng trền 62 đối tượng được chẩn đoán xác định là viêm kết mac di ứng theo mùa và viêm kết mạc dị ứng quanh nămtại Bệnh viện Mắt Nghệ An từ tháng 4/1999 đến tháng $8 / 2020$. Bệnh nhân được điêuu trị bằng nước mắt nhân tạo không có chất bảo quản (Vismed) nhỏ mắt ngày 4 lần, theo dõi trong 3 tháng tai các thời điểm sau 1 tuần, sau 1 tháng và sau 3 tháng điêuu trị. Kết quả cho thấy điểm trung bình các triệu chứng (ngứa, sợ ánh sáng, chảy nước mắt, sưng nề mi, cương tụ kết mạc và viêm chấm biểu mô) đêu giảm dần có ý nghĩa thống kê sau 1 tuần, 1 tháng và sau 3 tháng điêu trị bằng nước mắt nhân tạo Vismed $(p<0,001)$. Tỷ lệ bệnh nhân khỏi bênh tăng lên từ sau 1 tuần điều trị, đêến sau 3 tháng điều trị hầu hết bệnh nhân đều khỏi bệnh, sau 3 tháng điều trị chỉ còn 3 bệnh nhân $(4,8 \%)$ đớ các triệu chứng của bệnh. Nghiên cứu đã chî ra được hiệu quả của nước mắt nhân tạo không có chất bảo quản trong việc điều trị viêm kêt mạc dị ứng thểtheo mùa và quanh năm.

Từ khóa: Viêm kết mạc dị ứng, Viêm kết mạc dị ứng theo mùa, Viêm kết mạc dị ứng quanh năm, nước mắt nhân tạo, chất bảo quản.

\footnotetext{
*Sở Y tế Nghê An,

**Bệnh viền Mắt Nghệ An

Chịu trách nhiệm chính: Nguyễn Hữu Lê

Email: lebvmna@gmail.com

Ngày nhận bài: 9.8.20251

Ngày phản biện khoa học: 1.10 .2021

Ngày duyệt bài: 11.10.2021
}

\section{SUMMARY \\ EFICACY OF NON-PRESERVATIVE \\ ARTIFICIAL TEARS IN THE TREATMENT OF SEASONAL ALLERGIC CONJUNCTIVITIS AND PERENNIAL ALLERGIC CONJUNTIVITIS}

The clinical form of seasonal, perennial allergic conjunctivitis of allergic conjunctivitis is often overlooked, easily confused with transient irritation of the eye with wind, dust, or conjunctivitis caused by infectious factors. In fact, when diagnosed, patients will be treated immediately with anti-allergic drugs while not really needed. Descriptive study, clinical intervention comparing before, after and without control on 62 subjects with confirmed diagnosis of seasonal allergic conjunctivitis and perennial allergic conjunctivitis at Nghe An Eye Hospital since May. April 1999 to August 2020. Patients were treated with artificial tears without preservatives (Vismed) eye drops 4 times a day, followed up for 3 months at the time points after 1 week, after 1 month and after 3 months of treatment. The results showed that the mean scores of symptoms (itching, photophobia, lacrimation, eyelid swelling, conjunctival edema and punctate epithelitis) all decreased statistically significantly after 1 week, 1 month and after 3 months of treatment with Vismed artificial tears $(p<0.001)$. The rate of patients recovered increased from 1 week of treatment, to after 3 months of treatment, most of the patients were cured, after 3 months of treatment only 3 patients $(4.8 \%)$ were relieved of their symptoms. Research has shown the effectiveness of non-preservative artificial tears in the treatment of seasonal and perennial allergic conjunctivitis.

Keywords: Allergic conjunctivitis, Seasonal allergic conjunctivitis, Perennial allergic conjunctivitis, artificial tears, preservatives.

\section{I. ĐẶT VẤN ĐỀ}

Viêm kết mạc dị ứng (VKMDU) là một bệnh 